\title{
Appendix Mucinous Adenocarcinoma
}

National Cancer Institute

\section{Source}

National Cancer Institute. Appendix Mucinous Adenocarcinoma. NCI Thesaurus. Code C43558.

An adenocarcinoma arising from the appendix, characterized by the presence of mucinous stroma formation. 